\title{
Drivers' Speed Citation Involvement in Five Arabian Gulf Countries
}

\author{
HASHIM M. N. AL-MADANI
}

Center for Transport and Road Studies

College of Engineering, University of Bahrain

\begin{abstract}
This study investigates the association between drivers' characteristics and their speed citation involvement. Besides driving experience and accident involvement, the studied characteristics include monthly income, age, level of education, marital status and gender type. In order to model the above parameters; regression analysis was carried out to data gathered from 4774 drivers from five Arabian Gulf Cooperation Council (GCC) countries. The data were collected using a questionnaire involving short answers on the required characteristics. Official records were not possible to be used since they do not properly represent the actual drivers' population, simply because of the considerable amount of tickets issued to the owners of the vehicles rather than to the violating drivers. However, the gathered data on speed citations were possible to be compared indirectly with that officially published. The two matched reasonably well. The final developed model showed drivers' age, accident involvement, and monthly income to be significantly associated with speed citation involvement. Age showed a negative association and the other two parameters showed positive associations. In the presence of these variables, all the remaining variables become unbalanced and are automatically removed form the model. In the absence of age, driving experience and level of education become significant. The former is negatively associated with speed citations and the latter positively. The findings are believed to be important for law enforcers, driving rehabilitators, insurance decision makers, and traffic policy makers.
\end{abstract}

\section{Introduction}

Networks of high standard, using latest available facilities such as SCOOT, SATURN and TRANSIT systems, support the highway systems in GCC 
countries. Yet, safety records clearly vary from one state to another. The rates in Bahrain showed 8.8 fatalities per 100 thousand population and 2.9 per 10 thousand vehicles during the years 1995 to 1998 , which are closely comparable to those observed in many Western countries. The above rates for Oman are 19.8 and 13.4, for the UAE are 31.8 and 23.8, for Kuwait are 18.3 and 3.7, and for Qatar are 15.7 and 4.2, respectively. The rates in UK [1] are 6.4 and 1.4, in Turkey are 10.8 and 12.9, in Germany are 12.3 and 2.7, in the United States are 15.6 and 2.1, and in Spain are 16.3 and 3.6 [2], respectively. Over fifteen percent of the fatalities in GCC countries are solely due to overspeeding. In Bahrain the proportion of speed offences to total number of offences is $17 \%$ and speed offences per accident involvement is 0.24 . In UAE these are $20.4 \%$ and 5.4, respectively. Other population characteristics of the studied countries are presented in Table 1. Forsyth and Silcock [3] studied records of a large number of offences in Northumberia (U.K) and found $25 \%$ of the primary offences are caused by speeding. The rates of offences were 1.58 and 1.50 per accident and per person, respectively. Males' involvement was $81 \%$ and that of females $19 \%$.

According to Kleoden and McLean [4] risk of involvement in causality crash doubles with each 5-kph increase in speed above $60 \mathrm{kph}$. Many other studies showed other forms of relationships between the speed and the accident involvement as well. For example, some showed that a 1-kph increase in the mean speed causes 2 to 3 percent increase in the number of injury accidents [5]. Furthermore, as the mean speed increases the number of injury accidents increases quadratically and the number fo fatal ones as the power of four with respect to the speed [6].

Table 1: Population characteristics of the studied countries (1995)

\begin{tabular}{|l|c|c|c|c|c|}
\hline \multicolumn{1}{|c|}{ Parameter } & $\begin{array}{c}\text { Bahrain } \\
{[18,19]}\end{array}$ & $\begin{array}{c}\text { Oman } \\
{[18,23]}\end{array}$ & $\begin{array}{c}\text { UAE } \\
{[20,24]}\end{array}$ & $\begin{array}{c}\text { Kuwait } \\
{[18,25]}\end{array}$ & $\begin{array}{c}\text { Qatar } \\
{[18,26]}\end{array}$ \\
\hline Population (1000) & 578 & 2018 & 1785 & 1576 & 593 \\
\hline Males (\%) & 57.9 & 58.4 & NA & 58.0 & 67.2 \\
Females (\%) & 42.1 & 41.6 & NA & 42.0 & 32.8 \\
\hline Locals (\%) & 63.6 & 73 & 15 & 41.6 & 34.5 \\
Expatries (\%) & 36.4 & 27 & 85 & 58.4 & 65.5 \\
\hline Population Under 19 Years & 38.9 & 47.8 & 28.9 & 45.3 & 34.0 \\
(\%), 20to 59 Years (\%), & 57.3 & 48.3 & 68.6 & 52.5 & 64.2 \\
60+ Years (\%) & 3.8 & 3.9 & 2.3 & 2.2 & 1.8 \\
\hline Fatalities per 100,000 & 9.2 & 19.8 & 31.8 & 18.3 & 15.0 \\
population, 10,000 Vehicles & 3.1 & 13.4 & 23.8 & 3.7 & 4.2 \\
\hline Gross National Product & 8425 & 5696 & 16894 & 13572 & 12833 \\
(US \$ per capita) & 14.1 & 30.5 & NA & 17.6 & 22.4 \\
\hline Illiteracy (\%) & & & & & \\
\hline
\end{tabular}

NA Data not available. 
Mannering [7], on the other hand, studied only 200 drivers and found the number of moving violations per male and female drivers to be 1.03 and 0.96 , respectively. Lam and Kloeckner [8] found the main age group of speed limit offenders to be between 35 and 44 years, followed by the age group of 25 to 34 years. They have also concluded that proper enforcement on speed limits will reduce the number and severity of accidents. Peck and Kuan [9] found previous driving violation records, among other factors, to be useful predictors of future crash rates. Evans [10] and Evans et al, [11] reported that $28 \%$ of the drivers with violations (most commonly speed limit violations) were observed to follow short headways compared to $22 \%$ for the violation free drivers. Also short headways indicate risk taking but the reverse is not necessarily true.

Younger women were shown to be less patient than older women, with higher tendency to speed, tailgate and overtake on wrong side [12]. Young masculines are caught in speed offences more frequently than the older ones.

\section{Aims and Hypotheses}

This study investigates the relationship between drivers' characteristics and their involvement in speed citations. Besides driving experience and accident involvement, the studied characteristics includes age, monthly income, gender type, marital status and level of education. Accordingly a model is developed representing driver's speed citation involvement as a dependent variable versus the above independent variables to identify the association of the significant parameters more clearly. On the other hand, insignificant parameters can also be visualized.

It is obvious that novice and less experienced drivers are involved in greater numbers of traffic violations compared to better-experienced drivers. Similarly those less frequently involved in accidents might be involved in fewer traffic citations compared to those more frequently involved, simply because of being more cautious. Likewise is the case for female drivers compared to male ones. This is because of their lower exposure rates and greater respect to traffic laws. Married drivers are expected to be involved in lesser citations compared to singles because of greater social and economic constraints. Although the proposed relationship between married and unmarried drivers seems odd and has rarely been considered in such studies, yet it is nessary to be considered here because of the social and cultural differences compared with Western societies. As age and level of education increase, speed offences are expected to decrease because of better awareness. As income increases, so do the speed offences. Wealthier drivers own better, more luxurious, and higher power engine cars compared to poorer ones. These may encourage over speeding. Furthermore, they care less for being panalized in terms of money. 


\section{Methodology}

\subsection{Study Approach}

The study attempts to investigate the significance, magnitude and direction of the association of the above predictors with citations' involvement using least square linear regression analysis [13]. However, the parameters are first analyzed using Pearson correlation test to identify the correlation strength between the various variables. In order to gather the above-mentioned information, the study employs questionnaires to be filled out by the drivers. This is because the official data, as will be discussed in the next section, are not sufficiently representative. Nevertheless, all the predictors are first regressed regardless of their significance. Knowing the relative influence of each predictor, they are further analyzed using forward and stepwise regression. These methods construct the model by adding the independent variables one at a time. The order of inclusion is determined by respective contribution of each variable to explained variables. In this study the predictor with highest $t$-value is added to the model in each step. The process stops when the list includes no further significant variables at 0.05 levels.

Two methods are employed in modelling the predictors. The first (Table2) uses the absolute values of each predictor as collected from the questionnaires. For example, the driver fills in his monthly income by writing down the numbers matching his monthly wage. In order to sufficiently control the variabilities in the predictors between the various countries under consideration and to generalize the model a second method is employed. In this method each nonfactorial predictor is normalized to the mean value of the country (Table 2). For example, driver's monthly income, in each country, is adjusted by dividing it by the average monthly income of the drivers in the country.

While age, years of driving experience, accident involvement, monthly income (tax free) and level of education are treated as continuous variables; gender and marital status are considered as dichotomous variables. Gender took a value of zero for women and 1 for men; marital status took a value of zero for single and 1 for married.

\subsection{Official Speed Offences}

Although, one may gain enormous amount of information from official records, yet, it requires a cautious approach to consider it as representative. Drivers' characteristics with respect to traffic citations, for example, based on official records might lead to seriously biased conclusions, simply because of the considerable number of tickets, at least in this part of the world, issued 
against the owners of the vehicles rather than the violating drivers [10]. The violating driver might be some one other than the owner himself, like his son, daughter, wife or a friend. The records also lack in-depth details of the drivers' socioeconomic characteristics as their income, level of education, and family details. In order to overcome such deficiencies, the necessary data are to be collected independently through questionnaires. However, self-reported data present a number of potential problems, as well. These include the possibility of not accurately recalling accident and citation involvements [7]. Some might even give false information. The solution to this problem would be to compare them with actual data records. Unfortunately, such records were not available in most of the countries under study. However, to be able to measure the reliability of the collected data indirect comparisons were possible, as will be shown later, in some of the countries.

Table 2: Parameters involved in developing the models

\begin{tabular}{|l|l|l|}
\hline Parameters & \multicolumn{1}{|c|}{ Method 1 } & \multicolumn{1}{|c|}{ Method 2 } \\
\hline $\begin{array}{l}\text { Dependent } \\
\text { Variable }\end{array}$ & $\begin{array}{l}\text { Speed citation } \\
\text { involvement (three years } \\
\text { total) }\end{array}$ & Speed citatin involvement (three years total). \\
\hline $\begin{array}{l}\text { Independent } \\
\text { Variables }\end{array}$ & Driver's age (years) & $\begin{array}{l}\text { Drivers age per country's mean age of the } \\
\text { drivers }\end{array}$ \\
\cline { 2 - 4 } & $\begin{array}{l}\text { Driving experience } \\
\text { (years) }\end{array}$ & $\begin{array}{l}\text { Driving experience (years) per country's mean } \\
\text { driving experience (years) of the drivers. }\end{array}$ \\
\cline { 2 - 4 } & $\begin{array}{l}\text { Driver's accident } \\
\text { Involvement (life time) }\end{array}$ & $\begin{array}{l}\text { Driver's life time accident } \\
\text { Involvement per country's mean accident } \\
\text { involvement of the drivers. }\end{array}$ \\
\cline { 2 - 3 } & $\begin{array}{l}\text { Driver's monthly income } \\
\text { (Bahraini Dinars - B.D = } \\
\text { U.S.\$ 2.65) }\end{array}$ & $\begin{array}{l}\text { Driver's monthly income per country's mean } \\
\text { income of the drivers. }\end{array}$ \\
\cline { 2 - 3 } & $\begin{array}{l}\text { Driver's level } \\
\text { education (years) }\end{array}$ & $\begin{array}{l}\text { Driver's level of education (years) per country's } \\
\text { mean years of education of the drivers. }\end{array}$ \\
\cline { 2 - 3 } & $\begin{array}{l}\text { Marital status (married) } \\
\text { Gender (men) }\end{array}$ & $\begin{array}{l}\text { Marital status (married) } \\
\text { Gender (men) }\end{array}$ \\
\hline
\end{tabular}

\subsection{The Questionnaire}

Method of stratified choice-based random sampling technique is considered in administering the questionnaires on the drivers $[14,15]$. The stratification was proportioned based on the occupation. The occupation was stratified according to the following twelve categories: economic \& finance, private business, education, students, judiciary \& security, information \& tourism, health, social \& agriculture, industry \& electricity, transportation \& 
communication, unemployed, and other sectors. These classifications match with those published in the official statistical abstracts of the studied countries. Beside stratification benefits the technique provides other advantages over simpler sampling techniques as those employing household or roadblock surveys. Some of the advantages are associated with the social constraints in some of the considered countries. These include direct administration of the questionnaires to female respondents.

The questionnaire involved short answers' questions. These were designed to identify drivers' personal, traffic and socioeconomic characteristics along with their speed citation involvements. These covered the following parameters: age, sex, marital status, monthly income, education, nationality, occupation, driving experience, car ownership, frequency of seat-belt usage, accident involvement, and citations received in the past three years.

The drivers were instructed to record their speed citations for the last three years. The citation involvement for the drivers having less than three years of experience were then adjusted, as per annual average, to indicate three years total. Drivers' characteristics included the following: age (years), driving experience (years), level of education (years), accident involvement $(0,1,2,3$, $4,5,6$, or over), monthly income (as per currency of each country, then it is converted to Bahraini Dinars; B.D = US \$ 2.65), gender type, and marital status. The questionnaires were usually left with the respondent for a couple of days before being collected. The suitability of the questionnaire was reviewed by a group of four language and educational experts, form the University of Bahrain, before being distributed. The questionnaires were then distributed to the various occupational sectors in each country according to their proportion in the country. For example, if $15 \%$ of the population in Bahrain is involved in the economic and financial business, then $15 \%$ of the questionnaires allocated for Bahrain are to be distributed to the drivers in this sector. Well trained, M.Sc. and senior level B.Sc. students, in cooperation with traffic police and public works directorates in the various states, participated in distributing and collecting the questionnaires. This helped in having consistent responses from all the considered countries. The task, which was first started in Bahrain in 1995, took over thirty months to finish.

\section{Gathered Data}

\subsection{Response rate}

The questionnaire was distributed to around 9000 drivers in Bahrain, Qatar, Kuwait, Oman and Abu Dhabi representing United Arab Emirates (UAE), 4774 drivers responded. An overall response rate of $54 \%$ was achieved. The rates in 
each of the studied countries were as follows: $76 \%$ in Oman, $57 \%$ in Kuwait, $52 \%$ in Bahrain, $50 \%$ in Qatar, and 39\% in the UAE. This represents about 0.05 percent of the total number of vehicles registered in each state. Both the response and the response rate are thought to be sufficient for the analysis [16, 17]. The averages of the involved personal and socioeconomic variables for each of the considered countries are presented in Table 3.

Table 3: Drivers' averages for the studied parameters

\begin{tabular}{|l|c|c|c|c|c|c|}
\hline Country & $\begin{array}{c}\text { Age } \\
\text { (years) }\end{array}$ & $\begin{array}{c}\text { Monthly } \\
\text { Income } \\
\text { (B.D = US } \\
\$ 2.65)\end{array}$ & $\begin{array}{c}\text { Driving } \\
\text { Experience } \\
\text { (years) }\end{array}$ & $\begin{array}{c}\text { Accidents } \\
\text { (Life time) }\end{array}$ & $\begin{array}{c}\text { Level of } \\
\text { Education } \\
\text { (years) }\end{array}$ & $\begin{array}{c}\text { Speed } \\
\text { Citations } \\
\text { (in 3 } \\
\text { years) }\end{array}$ \\
\hline Kuwait & 32.5 & 579.7 & 11.2 & 1.4 & 14.1 & 0.7 \\
\hline Oman & 28.5 & 433.5 & 8.4 & 0.9 & 12.2 & 1.0 \\
\hline Qatar & 35.9 & 559.2 & 13.1 & 1.4 & 14.1 & 0.4 \\
\hline UAE & 40.2 & 886.1 & 16.4 & 1.3 & 15.1 & 1.1 \\
\hline Bahrain & 33.2 & 401.9 & 10.5 & 1.5 & 13.8 & 0.2 \\
\hline Overall & 33.9 & 582.7 & 11.9 & 1.3 & 13.8 & 0.7 \\
\hline
\end{tabular}

\subsection{Official versus gathered speed citations}

The official data available were not sufficient to directly check on the accuracy of the collected data. The drivers' population, for example, was not possible to be accurately estimated because of the presence of a high percentage of expatriates. These are continuously changing since the majority of the laborers work for few years then return back to their respective countries. Although the data in most of the considered countries are computerized, yet drivers who leave the country and those who pass away are not excluded from the official drivers' list. However, citations per passenger cars were possible to be estimated quite accurately in Bahrain and in UAE, but not in the other Gulf Countries due to the lack of official data on speed citations.

Assuming that each passenger car is owned, or driven, by at least one driver, the minimum number of speed citations received by a driver can be determined through the official records by dividing the number of speed citations (SPDCIT) issued annually by the number of registered passenger cars (RGSRPC). Furthermore, SPDCIT and RGSRPC determined through official sources are considered for the sample years as that considered by the respondent in the questionnaires. According to Bahrain Statistical Abstracts [18, 19], SPDCIT issued annually in Bahrain, average of three years, equals to 7081 citations and RGSRPC equals to 126683 passenger cars. Consequently, the average number of speed citations issued per driver per year equals to 0.0559 , 
or 56 per thousand drivers. This figure can now be compared with that determined through the questionnaires (Table 3). In fact, even a better comparison can be achieved by considering the respondents who actually own or posses, a car. The annual average number of speed citation involvement by the drivers in Bahrain was found to be 0.0656 , or 66 per one thousand drivers. This is slightly higher than the overall value shown in Table 3 after being divided by three to determine the annual rate, i.e. one third of 0.189 . The former is greater than the minimum rate obtained earlier through official records by only $15 \%$. The difference is even less when all the respondents are considered. However, the difference might partly be due to the inflated number of registered vehicles officially published. The latter might be less than the vehicles actually running on the streets. For example, some might not be in use for some reasons, as being handicapped because of accidents or serious breakdowns, and some are out of the country. Likewise, SPDCIT and RGSRPC for UAE, for the year 1992/93 [20], are 94,000 citations and 257,700 passenger cars, respectively. The corresponding speed citations per driver equals to 0.365 . Comparing it with 0.372 , which is obtained through the questionnaire, a difference of fewer than $2 \%$ is observed between the two rates.

\section{Results and Discussion}

Results from Pearson correlation test showed all the considered predictors except driving experience and marital status to be significantly correlated to drivers' speed citation involvement at 0.01 levels (Table 4). The correlation also revealed the direction of the relationship, negative for age and years of education and positive for the remaining significant parameters.

When all the predictors shown in Method 1 of Table 2 are considered in modeling drivers' speed citation involvement, the following parameters showed significant association at 0.05 level of significance (Table 5): age, accident involvement, monthly income and driving experience. Age showed a negative association with speed citation and the remaining significant parameters showed positive associations. In the presence of these parameters all other parameters become insignificant. The direction of the relationship of all the parameters matched with the hypotheses enunciated earlier except for the experience. The latter might be due to the differences in the mean years of driving experience between the different countries under consideration. The presence of age also influences the experience because of the significant correlation between the two. However, when the age parameter was removed, the experience became barely significant, with a negative association. Moreover, drivers' level of education also became significant with a negative influence in relation to speed citation. 
Table 4 Correlation Matrrix of the considered

\begin{tabular}{|c|c|c|c|c|c|c|c|c|c|}
\hline & & \begin{tabular}{|c|} 
SPEED \\
CITATIO \\
$\therefore \quad \mathrm{S}$ \\
RECIEVE \\
D IN \\
3YEARS
\end{tabular} & AGE & $\begin{array}{c}\text { DRIVING } \\
\text { EXPERIEN } \\
\text { CE }\end{array}$ & \begin{tabular}{|l} 
INVOLVE \\
ACCIDENT
\end{tabular} & SALAR & $\begin{array}{l}\text { YEARS } \\
\text { EDUCATION }\end{array}$ & MARRIED & MALE \\
\hline \multirow{3}{*}{$\begin{array}{l}\text { SPEED } \\
\text { RECIEVED IN }\end{array}$} & Pearson Correlation & 1.000 & $-.103^{*}$ & -.007 & $.164 *$ & $.105^{*}$ & $-.043^{*}$ & -.020 & $.048^{* *}$ \\
\hline & Sig. (2-tailed) & & .000 & .682 & .000 & .000 & .012 & .238 & .005 \\
\hline & $\mathrm{N}$ & 3459 & 3423 & 3459 & 3442 & 2266 & 3417 & 3406 & 3438 \\
\hline \multirow[t]{3}{*}{ AGE } & Pearson Correlation & $-103^{\star \star}$ & 1.000 & $.719^{\star \star}$ & .089 * & .286 * & $.233^{* \star}$ & .560 ** & $.282^{\text {* }}$ \\
\hline & Sig. (2-tailed) & .000 & & .000 & .000 & .000 & .000 & .000 & .000 \\
\hline & $\mathrm{N}$ & 3423 & 4696 & 4229 & 4621 & 3091 & 4621 & 4580 & 4635 \\
\hline \multirow{3}{*}{ DRIVING } & Pearson Correlation & -.007 & $.7199^{*}$ & 1.000 & $.154 *$ & $.375 *$ & $.170^{* *}$ & .425 ** & $.261^{\text {** }}$ \\
\hline & Sig. (2-tailed) & .682 & .000 & & .000 & .000 & .000 & .000 & .000 \\
\hline & $\mathrm{N}$ & 3459 & 4229 & 4282 & 4242 & 2909 & 4222 & 4206 & 4247 \\
\hline \multirow{3}{*}{ INVOLVED } & Pearson Correlation & $.164^{* \star}$ & .089 * & $.154^{* \star}$ & 1.000 & .081 * & .023 & $.092^{* *}$ & $.131^{\text {* }}$ \\
\hline & Sig. (2-tailed) & .000 & .000 & .000 & & .000 & .119 & .000 & .000 \\
\hline & $\mathrm{N}$ & 3442 & 4621 & 4242 & 4694 & 3095 & 4620 & 4599 & 4653 \\
\hline \multirow[t]{3}{*}{ SALAR } & Pearson Correlation & $.105^{* \star}$ & .286 * & $.375^{\text {*夫 }}$ & .081 * & 1.000 & $.318^{* *}$ & .162 ** & .138 *夫 \\
\hline & Sig. (2-tailed) & .000 & .000 & .000 & .000 & & .000 & .000 & .000 \\
\hline & $\mathrm{N}$ & 2266 & 3091 & 2909 & 3095 & 3127 & 3085 & 3072 & 3099 \\
\hline \multirow[t]{3}{*}{ YEARS OF } & Pearson Correlation & $-.043^{*}$ & $.233 *$ & $.170^{* \star}$ & .023 & .318 * & 1.000 & $.152^{* \star}$ & .001 \\
\hline & Sig. (2-tailed) & .012 & .000 & .000 & 119 & .000 & & .000 & .969 \\
\hline & $\mathrm{N}$ & 3417 & 4621 & 4222 & 4620 & 3085 & 4691 & 4579 & 4639 \\
\hline \multirow[t]{3}{*}{ MARRIED } & Pearson Correlation & -.020 & .560 * & $.425^{* \star}$ & .092 * & .162 * & $.152^{* *}$ & 1.000 & .199 ** \\
\hline & Sig. (2-tailed) & .238 & .000 & .000 & .000 & .000 & .000 & & .000 \\
\hline & $\mathrm{N}$ & 3406 & 4580 & 4206 & 4599 & 3072 & 4579 & 4652 & 4615 \\
\hline \multirow[t]{3}{*}{ MALE } & Pearson Correlation & $.048^{* \star}$ & $.282 *$ & $.261^{\star \star}$ & .131 * & .138 * & .001 & $.199^{* *}$ & 1.000 \\
\hline & Sig. (2-tailed) & .005 & .000 & .000 & .000 & .000 & .969 & .000 & \\
\hline & $\mathrm{N}$ & 3438 & 4635 & 4247 & 4653 & 3099 & 4639 & 4615 & 4709 \\
\hline
\end{tabular}

${ }^{* *}$. Correlation is significant at the 0.01 level (2-

*. Correlation is significant at the 0.05 level (2- 
Table 5: Coefficient estimates for significant predictors in speed citation model

\begin{tabular}{|l|l|c|c|}
\hline \multicolumn{1}{|c|}{ Significant predictors (at 0.05 level) } & Coefficient & Standard error & $\mathrm{t}$-test \\
\hline Constant & 1.234 & 0.114 & 10.862 \\
\hline Age (Years) & -0.032 & 0.004 & -8.247 \\
\hline Driving experience (Years) & 0.0112 & 0.005 & 2.270 \\
\hline Accident involvement (Number) & 0.141 & 0.020 & 6.886 \\
\hline Monthly income (B.D=U.S.\$ 2.65) & $3.340 \times 10^{-4}$ & 0.000 & 6.070 \\
\hline
\end{tabular}

As has been mentioned earlier, in order to control the differences between the drivers in the different countries, all the parameters are remodeled after the responses from each county are individually normalized to the countries' mean values, according to Method 2 in Table2. Once again the results (Table 6) confirmed the previous findings with the exception that driving experience becomes insignificant this time in the presence of the age. In fact in the presence of age, level of education is also insignificant. As a result of the two methods, one may simply consider the age, which is easily collected for such studies, to represent both driving experience and level of education, which are more difficult and time consuming in being gathered, without loosing the accuracy significantly. This will clearly drop the cost of data collection. The basic form of the improved model is illustrated by a linear regression equation. The model after being normalised to the countries' mean values, can be written in the following form:

Table 6: Coefficient estimates for significant normalized predictors in improved speed citation model

\begin{tabular}{|l|c|c|c|}
\hline Significant predictors (at 0.05 level) & Coefficient & Standard error & \multicolumn{1}{|c|}{ t-test } \\
\hline Constant & 1.290 & 0.118 & 10.915 \\
\hline $\begin{array}{l}\text { Age per country's mean age of the } \\
\text { drivers }\end{array}$ & -1.083 & 0.135 & -8.032 \\
\hline $\begin{array}{l}\text { Accident involvement per country's } \\
\text { mean accident involvement per driver }\end{array}$ & 0.238 & 0.026 & 9.198 \\
\hline $\begin{array}{l}\text { Monthly income per drivers' mean } \\
\text { monthly income in the country }\end{array}$ & 0.103 & 0.038 & 3.137 \\
\hline
\end{tabular}

Driver's speed citation involvement (three years total) $=$

$1.290-1.083$ Age (per mean driving age)

+0.238 Accident (per drivers' mean life time accident

involvement) +0.103 Monthly income (per drivers' mean

monthly income)

The direction of the associations matches that shown in the correlation matrix (Table 4). Although the above model indicated a sufficiently high $\mathrm{F}$ 
value $(F=25)$, yet one needs to be cautious in its application because of the low adjusted $\mathrm{R}^{2}$ value, which was around 0.1 . However, this is not uncommon in such studies $[21,22]$ because of the dispersive nature of the data and the clear variation in the responses between one driver and the other. Nevertheless, the direction of the association and the significance of the predictors are still very useful. It is also worth mentioning that sophisticated models may not add to the accuracy much for such dispersive natured data.

Although the above findings of young wealthy drivers being involved more in accidents and speeding tickets than others looks very obviuos in the developed countries, yet very scarce studies on such issues were found for the drivers in this part of the world.

\section{Conclusions and Recommendations}

Drivers' age, accident involvement and monthly income showed significant association with speed citation involvement. While age showed a negative association, accident involvement and monthly income showed positive associations. In the presence of these predictors, years of driving experience, level of education, gender type, and marital status showed no significant association with driver's speed citation involvement. However, as age is removed from the predicted model both level of education and years of driving experience become negatively significant with speed citations. Age may be considered to represent both experience and level of education. In order to generalize the findings and to control the differences between the drivers from one country to the other, all the parametric variables involved in the final developed model were normalized to the mean values of the studied countries.

In the light of these findings and from the general observation of the outcome several strategies might emerge in tackling a serious offense as speed violation. In terms of education, it is important to focus down on young age group to illustrate to them the consequences of not following the assigned speed limits. Also, it is important to warn parents on the consequences of buying "sport" cars for their children because in this part of world, the children still depend on their parents to finance the purchase of their cars. Also it is important to highlight that as the nation gets more educated, education in the general term, the awareness of violating speed limits will increase, as this study shows. Law enforcement should be adopted to suit the social and economical conditions in this part of the world. Ticket fines might not be suitable for the local conditions as this study showed that the higher the income of drivers the more tickets they receive. So the punishment might take other forms like: spending time in doing social work, taking intensive courses for some time on safety aspects which might be more effective for the purpose of deterring the drivers. 


\section{References}

[1] The Department of Transport, Road Accidents: Great Britain 1994-The Casualty Report. HMSO, UK (1995).

[2] Economic Commission for Europe, Statistics of Road Traffic Accidents in Europe and North America. Vol. XL, United Nations, Geneva (1995).

[3] Forsyth, E. and Silcock, D. T., The Relationship between Road Accidents and Prosecutions for Traffic Offences in the Northumbria Police Area. Traffic Engineering and Control, 29, 357-361, (1988).

[4] Kloenden, C. N. and Mc Lean, A. J., Speed and the Risk of Involvement in a Casualty Crash, Proceedings of Road Safety Conference on Research, Policing and Education, Wellington, Newzeland, vol. 1, pp 188-190, (1998).

[5] Antov, D., Speed Experiment in Estonia-Impact on Road Safety and Road User Behaviour, $10^{\text {th }}$ International Conference: Traffic Safety on Two Continents, Malmo, Swedish National Road and Transport Research Institute, Sweden (1999).

[6] Andersson, G. and Nilsson, G., Speed Management in Sweden, Swedish National Road and Transport Research Institute. Linkoping. Sweden (1997).

[7] Mannering, F. L., Male/Female Driver Characteristics and Accident Risk: Some New Evidence. Accident Analysis and Prevention, 25, 77-84, (1993).

[8] Lam, R. and Kloeckner, J. H., Increase of Traffic Safety by Surveillance of Speed Limits with Automatic Radar Devices on a Dangerous Section of a German Autobahn: A Longterm Investigation. Transportation Research Record, 974, 8-16 (1988).

[9] Peck, R. C. and Kuan, J. A., A Statistical Model of Individual Accident Risk Prediction Using Driver Record, Territory and Other Biographical Factors. Accident Analysis and Prevention, 15, 371-393, (1983).

[10] Evans, L., Traffic Safety and the Driver. Van Nostrand Reinhold, New York, (1991).

[11] Evans, L.; Wasielewski, P. and Van Buseck, C. R., Compulsory Seat Belt Usage and Driver Risk-Taking Behavior. Human Factors, 24, 41-48, (1982).

[12] Dyson, C., Contrasting Views within Australia on Which Factors Drive the Reduction in Numbers of Serious Road Casualties. $10^{\text {th }}$ International Conference: Traffic Safety on Two Continents, Malmo, Swedish National Road and Transport Research Institute. Sweden (1999).

[13] Norusis, M.J., SPSS Advanced Statistics, 6.1. Chicago, I.L: SPSS, Inc., (1996).

[14] Stopher, P. R and Meyburg, A. H., Survey Sampling and Multivariate Analysis for Social Scientists and Engineers. San Francisco, Lexington Books, (1970).

[15] Ortuzar, J. D. and Willumsen, L. G., Modeling Transport. New York: Wiley, (1996).

[16] Dean, J., Basic Statistics for Social Research. Macmillan. New York (1981).

[17] Steven, K., Sampling. John Wiley. New York, (1992).

[18] General Statistics Organization, Statistical Abstract 1995. Directorate of Statistics, Bahrain, (1996).

[19] Traffic and Licensing Directorate, Traffic Accidents Facts in State of Bahrain. Ministry of Interior, Bahrain, (1995).

[20] Khamees, A. A.; Jamal, A. A.; Al-Eter, H. A.; Al-Sayed Rizg, Z and Hasan, O. A., The Vehicle and the Road. Center for Security and Social Research and Studies. (In Arabic) Interior Ministry, AbuDhabi, UAE, (1995).

[21] Johansson, G. and Backlund, F., Drivers and Road Signs. Ergonomics, 13, 749-759, (1970).

[22] Shinar, D; Dewar, R; Summala, H. and Zkowska, L., Highway Traffic Sign Comprehension: A Cross-cultural Study. $10^{\text {th }}$ International Conference, Traffic Safety on Two Continents, Swedish National Road \& Transport Research Institute (VTI), Sweden, (1999). 
[23] Ministry of Development, General Census of Population, Housing and Establishnent, Sultanate of Oman, 1995.

[24] Department of Planning, Abu Dhabi in Figures, United Arab Emarates, 1995.

[25] Central Statistical Office, Statistical Review, Ministry of Planning, State of Kuwait, 1997.

[26] Central Statistical Organization, Annual Statistical Abstracts. Presidency of the Council of Ministers. State of Qatar, 1995. 


\title{
تقديرمخالفلت للسرعة للسائمن في خهس دول خليجية
}

\author{
هاثم محمد نور المدي \\ مركزدرلسلت المواصلات والطرق, كلية الهنهة, جلمعة البحرين \\ المستخلص: تبحث هذه الدرلسة في العلاقة بين خواص اللسائمن

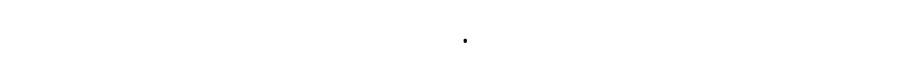

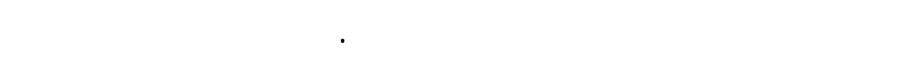

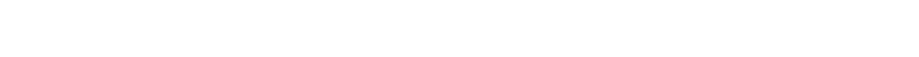

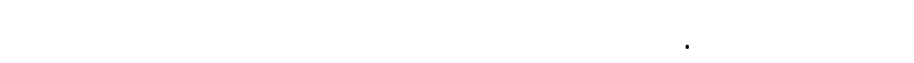

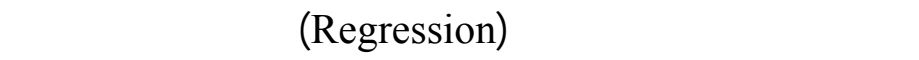

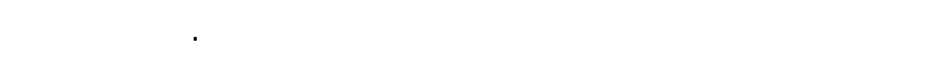

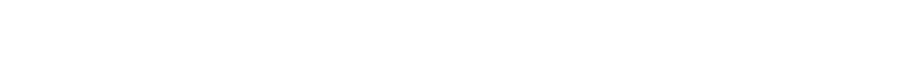

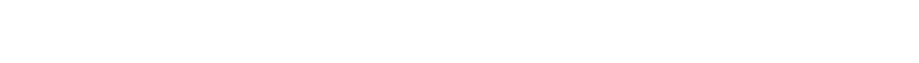

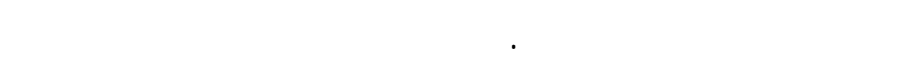

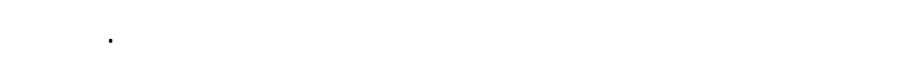

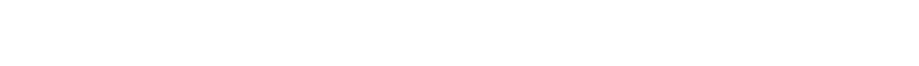

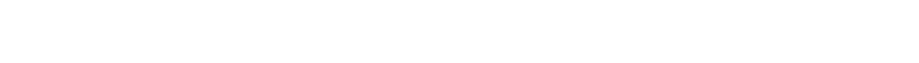

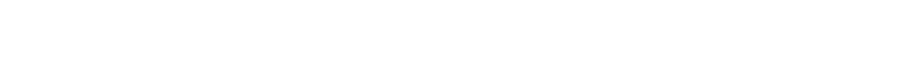

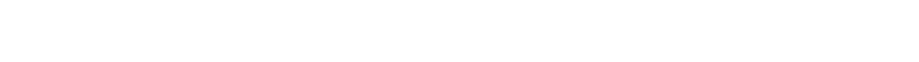 \\ مخالفلت للسرعة. وقد كلن ارتبط مخالفلت السرعة بالعمرسلبيًا،

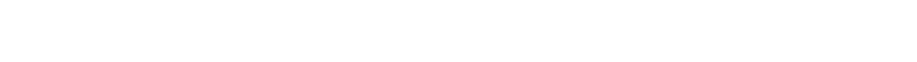

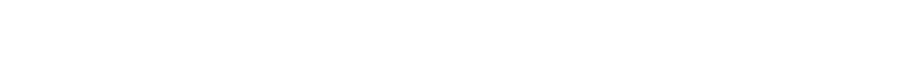

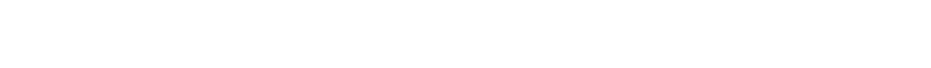

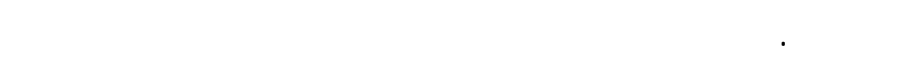

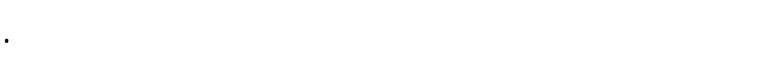

